\title{
EFEKTIFITAS LEMBAR PEMANTAUAN INSULIN TERINTEGRASI UNTUK MENGURANGI KEJADIAN HIPOGLIKEMIA PADA PASIEN DIABETES MELLITUS TIPE 2
}

\author{
Dikha Ayu Kurnia*, Debie Dahlia \\ Faculty of Nursing Universitas Indonesia, Depok 16424, Indonesia \\ *E-mail: dikha.ayukurnia@gmail.com
}

\begin{abstract}
Abstrak
Hipoglikemia merupakan salah satu efek samping pemberian terapi insulin pada pasien Diabetes Melitus tipe 2. Penelitian ini bertujuan untuk mengembangkan dan menguji keefektifan lembar pemantauan insulin terintegrasi dalam memantau kejadian hipoglikemia pada pasien DM tipe 2 yang mendapatkan terapi insulin analog. Hasil menunjukkan rerata kejadian hipoglikemia lebih tinggi saat makan pagi $(t(18)=2,9732 ; p=0,0059)$ dan sore $(t(18)=3.0956 ; p=$ 0,0043 ) setelah pemberian rapid-acting insulin melalui pemantauan lembar insulin terintegrasi Namun, hasil penelitian ini juga menunjukkan bahwa tidak ada hubungan signifikan antara pemantauan asupan kalori, dosis insulin, dan perubahan pola tidur dengan kejadian hipoglikemia. Sehingga lembar pemantauan insulin terintegrasi tidak efektif dalam mencegah kejadian hipoglikemia. Penelitian ini merekomendasikan perawat untuk lebih memahami pengkajian hipoglikemia dalam lembar pemantauan insulin terintegrasi.
\end{abstract}

Kata Kunci: Kejadian hipoglikemia, lembar pemantauan insulin terintegrasi, pasien DM Tipe 2, terapi insulin

\begin{abstract}
The Effectiveness of the Integrated Insulin Monitoring Sheets to Decrease Hypoglycemia Incidence on the Diabetes Mellitus Type 2 Patients. Hypoglycemia is one of the side effects of insulin therapy administration for Type 2 Diabetes Mellitus patients. The study aimed to develop the integrated insulin monitoring sheets and examine its effectiveness in identifying and recording the incidence of hypoglycemia who received analog insulin therapies. The results showed that the integrated insulin monitoring sheet recorded the significantly higher incidence of hypoglycemia during the morning $(t(18)=2.9732 ; p=0.0059)$ and evening $(t(18)=3.0956 ; p=0.0043)$ meals after the administration of rapid-acting insulin). The record integrated insulin monitoring sheet, revealed no significant relationships between the incidence of hypoglycemia and the monitoring of calorie needs, insulin therapy administration, blood glucose, and level insomnia incidences. This study recommended activities that enable nurses to better understand the assessment of hypoglycemia.
\end{abstract}

Keywords: Diabetes Mellitus Type 2 Patients, hypoglycemia, insulin therapy, the integrated Insulin Monitoring Sheet

\section{Pendahuluan}

Diabetes Melitus (DM) Tipe 2 merupakan penyakit metabolik kronis yang saat ini menempati urutan ke enam sebagai penyebab kematian pada orang dewasa (Center for Disease Control (CDC), 2007). Jumlah penderita DM diprediksi meningkat dari 1 juta di tahun 2000 menjadi 1,6 juta penderita di tahun 2016 (World Health Organization (WHO), 2008). Diabetes diketahui penderita setelah mengalami kompli- kasi akibat penyakit DM yang tidak terkontrol karena ketidakstabilan gula darah di mana sering terjadi kondisi hiperglikemia dalam waktu yang lama. Komplikasi kronik akibat DM dapat menyebabkan penyakit jantung, hipertensi, stroke, neuropati, retinopati, dan nefropati (Black \& Hawks, 2004).

Kadar glukosa darah yang tidak terkontrol merupakan salah satu penyebab terpenting terjadinya komplikasi. Tujuan pengobatan diabetes 
pada dasarnya adalah mengontrol glikemik atau gula darah hingga mencapai kadar gula yang mendekati normal. American Diabetes Association (2010) merekomendasikan sasaran pengobatan diabetes adalah nilai A1C di bawah 7\% $(70-130 \mathrm{mg} / \mathrm{dl})$. Meskipun demikian, pada kondisi tertentu sasaran kendali glikemik pada A1C di bawah 7,5\%. Terapi insulin merupakan metode yang direkomendasikan untuk dapat mengontrol kadar glikemik pada pasien diabetes dan memiliki nilai prediktif yang kuat untuk komplikasi diabetes (CDC, 2007; ADA, 2010; Rymaszewski \& Breakwell, 2013).

Berbagai macam tipe protokol insulin yang efektif untuk mengatasi hiperglikemia seperti sliding scale insulin, dan basal/prandial insulin di rumah sakit membutuhkan pemantauan kenyamanan dan kontrol glukosa yang aman. Hal ini dikarenakan pasien DM dapat memperoleh terapi insulin dengan jumlah penyuntikan per hari yang disesuaikan dengan kondisi kesehatannya. Sehingga pemantauan terapi insulin diperlukan untuk mengontrol kadar gula darah dan mencegah terjadinya hipoglikemia. Penelitian yang dilakukan oleh Rymaszewski dan Breakwell (2013) menyampaikan bahwa pemberian terapi insulin dengan tipe sliding scale dapat memberikan peluang terjadinya hipoglikemia yang berat dibanding dengan tipe basal/ prandial insulin. Sedangkan pemberian tipe basal/prandial insulin memberikan peluang terjadinya hipoglikemia yang rendah-sedang.

Hipoglikemia merupakan kondisi di mana kadar gula darah mencapai $<60 \mathrm{mg} / \mathrm{dL}$. Pasien yang dirawat di rumah sakit dapat mengalami kondisi hipoglikemia karena penurunan asupan kalori baik yang berhubungan dengan penyakit maupun yang berhubungan dengan rutinitas rumah sakit dan $32 \%$ kondisi hipoglikemia yang terjadi di rumah sakit merupakan kejadian yang tidak dapat dihindari (Fischer, 1986; Smith, et al., 2005). Untuk mengatasi kondisi tersebut dibutuhkan perencanaan perawatan individu setiap pasien untuk memantau perkembangan kadar glukosa darah. Lembar pemantauan kadar glukosa darah merupakan lembar integrasi yang terdiri dari pencatatan order pemberian dosis insulin, pencatatan jumlah kalori yang menunjukkan bahwa asupan makanan pasien untuk mengetahui tingkat hipoglikemia, dan penghitungan tipe terapi insulin yang digunakan baik basal, prandial, maupun correctional. Pendekatan standarisasi lembar order pemberian terapi insulin membuktikan keefektifan dalam pemberian terapi insulin dan mencegah kejadian hipoglikemia di beberapa institusi rumah sakit (Baldwin, et al., 2005; Trence, 2003; Furnary, 2004; Lien, et al., 2005). Perawat berperan penting dalam kualitas pencatatan lembar pemantauan terapi insulin. Hal ini dikarenakan dosis insulin dapat berubah bergantung pada tingkat sensitivitas insulin yang berhubungan dengan tingkat stres, interaksi obat, selera makan, dan intake oral terakhir makan (Braithwaite, 2007).

Rumah Sakit Fatmawati telah memiliki pencatatan glukosa darah sederhana yang hanya meliputi kadar glukosa darah dan jumlah insulin yang diterima. Namun, pencatatan tersebut belum terintegrasi dengan jumlah kalori yang masuk baik pada saat sarapan, makan siang, dan makan sore yang disesuaikan dengan kadar glukosa darah dan jumlah insulin yang diterima. Berdasarkan hal tersebut penelitian ini bertujuan untuk menjawab pertanyaan penelitian "Bagaimana efektivitas lembar pemantauan insulin terintegrasi dalam mengurangi kejadian hipoglikemia?"

Tujuan penelitian ini antara lain diketahuinya efektivitas lembar pemantauan insulin terintegrasi terhadap penurunan kejadian hipoglikemia pada pasien DM yang mendapatkan terapi insulin. Tujuan khusus dari penelitian ini adalah diketahui karakteristik pasien (umur, jenis kelamin, pendidikan, lama menderita DM, tipe terapi insulin) penyakit DM, diketahui proporsi kejadian hipoglikemia pasien DM dengan menggunakan lembar pemantauan insulin RS dan lembar pemantauan insulin terintegrasi, dan diketahui efektivitas lembar pemantauan insulin terintegrasi dalam mengurangi kejadian hipoglikemia. 


\section{Metode}

Penelitian ini menggunakan desain quasi experiment dengan pendekatan non-equivalent post test only control group, desain ini bertujuan untuk meneliti hubungan sebab akibat dengan cara memberikan intervensi (perlakuan) pada kelompok eksperimen, kemudian hasil (akibat) dari intervensi tersebut dibandingkan dengan kelompok kontrol.

Teknik pengambilan sampel dalam penelitian ini dilakukan dengan teknik non probability sampling dengan pendekatan consecutive sampling yaitu semua subjek yang datang dan memenuhi kriteria pemilihan dimasukkan sampai jumlah subyek yang ditetapkan dapat terpenuhi (Sastroasmoro \& Ismael, 2010). Kriteria inklusi sampel dalam penelitian ini adalah pasien DM Tipe 2 yang mendapat terapi insulin analog dan bersedia menjadi responden dengan lama penggunaan terapi insulin selama satu minggu (7 hari). Berdasarkan penelitian oleh Achtmeyer (2002) diketahui bahwa standar deviasi dari penelitian tersebut adalah 2, ratarata pada penelitian ini pada kelompok kontrol adalah 7,6 dan rerata pada kelompok intervensi adalah 9,6. Perhitungan sampel penelitian ini menggunakan uji hipotesis beda rerata dua kelompok independen dengan derajat kemaknaan $5 \%$ dan kekuatan $80 \%$, maka rumus pengambilan sampel menggunakan rumus oleh Sastroasmoro dan Ismael (2010), yaitu: $n 1=$ $n 2=2 Z \alpha+Z \beta s x 1-x 2 \quad 2=n 1=n 2=2 \quad 1,96+$ $0,84229,6-7,62=n 1=n 2=16$ orang. Untuk mengantisipasi drop-out, peneliti menambahkan sampel menjadi 20 orang untuk masingmasing kelompok kontrol dan kelompok intervensi.

Penelitian ini merupakan studi komparasi. Data hasil penelitian dianalisis dengan menggunakan uji $\mathrm{t}$ untuk mengidentifikasi perbedaan rerata kejadian hipoglikemia setelah diterapkan pemantauan dengan lembar pemantauan insulin terintegrasi. Penelitian ini dilakukan di ruang rawat penyakit dalam di sebuah RS. Rumah sakit ini merupakan rumah sakit pendidikan ti- pe A yang mendukung pengembangan dalam bidang penelitian. Selain itu, rumah sakit ini belum ada lembar pemantauan insulin terintegrasi dan laporan mengenai kejadian hipoglikemia pada pasien yang menggunakan terapi insulin. Penelitian ini dilaksanakan pada pertengahan Maret-Oktober 2014. Peneliti melakukan penelitian setelah mendapatkan izin dari kedua pihak yaitu pihak institusi pendidikan dan rumah sakit. Dalam melakukan penelitian, peneliti harus mempertimbangkan prinsip etik dan memberikan informed consent.

\section{Hasil}

Hasil data pada kelompok intervensi, yaitu kelompok pasien DM Tipe 2 yang memperoleh terapi insulin analog dengan menggunakan lembar pemantauan insulin terintegrasi dilakukan uji reliabilitas. Berdasarkan uji reliabilitas, nilai $r$ alpha $(0,727)$ lebih besar dibandingkan dengan nilai $r$ tabel $(0,312)$ sehingga pertanyaan dalam kelompok intervensi dinyatakan reliabel.

Karakteristik Responden. Karakteristik pasien yang menjadi responden dalam penelitian ini berdasarkan usia, jenis kelamin, tingkat pendidikan, dan status perkawinan, usia, lama menderita Diabetes Melitus (DM), dan lama dirawat di RS (lihat Tabel 1 dan 2). Sedangkan untuk data kebutuhan kalori tampak seperti yang ditunjukkan Tabel 3 dan 4. Data kebutuhan kalori diperoleh pada kelompok intervensi yang menggunakan lembar insulin terintegrasi.

Analisis bivariat menganalisis hubungan antara dua variabel yang ingin diteliti meliputi hubungan antara jenis insulin, hubungan asupan makanan dengan kejadian hipoglikemia. Pada hubungan antara jenis insulin dengan hipoglikemia hari ke-1 menunjukkan hasil: $F(39)=$ $0,01, p=0,9222$, di mana hasil tersebut menunjukkan hasil tidak signifikan antara jenis insulin dengan hipoglikemia hari ke-1. Sedangkan uji $\mathrm{F}$ untuk mengetahui hubungan antara jenis insulin dengan kejadian hipoglikemia hari ke-2 dengan hasil $\mathrm{F}(39)=1,14, \mathrm{p}=0,2933$ juga 
Tabel 1. Karakteristik Responden Berdasarkan Usia, Jenis Kelamin, Tingkat Pendidikan, dan Status Perkawinan

\begin{tabular}{|c|c|c|c|c|}
\hline \multirow{2}{*}{ Karakteristik } & \multicolumn{2}{|c|}{ Kontrol } & \multicolumn{2}{|c|}{ Intervensi } \\
\hline & $\mathbf{n}$ & $\%$ & $\mathbf{N}$ & $\%$ \\
\hline \multicolumn{5}{|l|}{ Jenis kelamin } \\
\hline Laki-laki & 8 & 40 & 9 & 45 \\
\hline Perempuan & 12 & 60 & 11 & 55 \\
\hline \multicolumn{5}{|l|}{ Pendidikan terakhir } \\
\hline Tidak tamat SD & 4 & 20 & 1 & 5 \\
\hline Tamat SD & 0 & 0 & 8 & 40 \\
\hline Tamat SLTP & 2 & 10 & 2 & 10 \\
\hline Tamat SLTA & 10 & 50 & 8 & 40 \\
\hline Tamat PT & 4 & 20 & 1 & 5 \\
\hline \multicolumn{5}{|l|}{ Diagnosis Medis } \\
\hline DM dengan penyakit penyerta & 20 & 100 & 17 & 85 \\
\hline DM tanpa penyakit penyerta & 0 & 0 & 3 & 15 \\
\hline
\end{tabular}

Tabel 2. Karakteristik Pasien Meliputi Usia, Lama Menderita DM, dan Lama Dirawat di Rumah Sakit

\begin{tabular}{lcccc}
\hline \multirow{2}{*}{ Karakteristik } & \multicolumn{2}{c}{ Kontrol } & \multicolumn{2}{c}{ Intervensi } \\
\cline { 2 - 5 } & Rerata & SD & Rerata & SD \\
\hline Usia (tahun) & 62,20 & 10,42 & 54,05 & 8,16 \\
Lama menderita DM (tahun) & 7,10 & 2,45 & 3,50 & 4,27 \\
Lama dirawat di RS (hari) & 8,55 & 5,31 & 4,55 & 1,54 \\
\hline
\end{tabular}

Tabel 3. Kebutuhan Kalori Kelompok Intervensi

\begin{tabular}{lcc}
\hline \multicolumn{1}{c}{ Kebutuhan Kalori Kelompok Intervensi } & Rerata & SD \\
\hline Total Kebutuhan Kalori & 1675,00 & 63,87 \\
Asupan Kalori Hari Ke-1 & 1569,30 & 318,97 \\
Asupan Kalori Hari Ke-2 & 1573,55 & 311,14 \\
Asupan Kalori Hari Ke-3 & 1569,93 & 287,38 \\
\hline
\end{tabular}

Tabel 4. Terapi Insulin yang Diberikan dan Kejadian Hipoglikemia pada Kelompok Kontrol dan Intervensi

\begin{tabular}{lcccccc}
\hline \multirow{2}{*}{ Terapi Insulin } & \multicolumn{2}{c}{ Kontrol } & \multicolumn{2}{c}{ Intervensi } & \multicolumn{2}{c}{ Total } \\
\cline { 2 - 7 } & $\mathbf{n}$ & $\mathbf{\%}$ & $\mathbf{n}$ & $\mathbf{\%}$ & $\mathbf{n}$ & \% \\
\hline Rapid Acting Insulin & 7 & 17,5 & 8 & 20,0 & 15 & 37,5 \\
Long Acting Insulin & 7 & 17,5 & 1 & 2,5 & 8 & 20,0 \\
Rapid dan Long-Acting Insulin & 6 & 15,0 & 11 & 27,5 & 17 & 42,5 \\
\hline
\end{tabular}


menunjukkan bahwa tidak ada hubungan antara pemberian jenis insulin dengan kejadian hipoglikemia hari ke-2. Jenis insulin dengan hipoglikemia hari ke-3: $\mathrm{F}(39)=0,31, \mathrm{p}=0,5793$ juga menunjukkan nilai $\mathrm{p}>0,05$ sehingga tidak ada hubungan yang signifikan antara jenis insulin dan kejadian hipoglikemia hari ketiga (lihat Tabel 5).

Uji t dilakukan untuk melihat adanya hubungan antara pemberian rapid acting insulin pada kejadian hipoglikemia pada hari pertama, di waktu sarapan, makan siang, dan makan sore yang ditampilkan dalam Tabel 6. Hasil data yang ada pada Tabel 6 menunjukkan bahwa terdapat hubungan yang signifikan antara pem- berian jenis rapid-acting insulin pada saat sarapan $(\mathrm{p}=0,0059)$ dan makan sore $(\mathrm{p}=0,0043)$. Hasil tersebut berbeda dengan pemberian jenis rapid-acting insulin pada saat makan siang ( $\mathrm{p}=$ 0,2765 ) di mana nilai $p>0,05$ sehingga tidak ada hubungan antara pemberian rapid-acting insulin saat makan siang dengan kejadian hipoglikemia.

Analisis multivariat pada penelitian ini tidak dapat diolah karena hasil dari analisis bivariat yang tidak signifikan antara asupan makanan, jenis insulin, dan perubahan pola tidur. Sehingga dapat disimpulkan bahwa lembar pemantauan insulin terintegrasi tidak efektif dalam mengurangi kejadian hipoglikemia.

Tabel 5. Terapi Insulin yang Diberikan dan Kejadian Hipoglikemia pada Kelompok Kontrol dan Intervensi

\begin{tabular}{|c|c|c|c|c|c|c|c|c|}
\hline \multirow{2}{*}{ Kejadian Hipoglikemia } & \multicolumn{2}{|c|}{ Kontrol } & \multicolumn{2}{|c|}{ Intervensi } & \multicolumn{2}{|c|}{ Total } & \multirow{2}{*}{$\mathbf{F}$} & \multirow{2}{*}{$\mathbf{p}$} \\
\hline & $\mathbf{n}$ & $\%$ & $\mathbf{N}$ & $\%$ & $\mathbf{n}$ & $\%$ & & \\
\hline \multicolumn{9}{|l|}{ Hari ke-1 } \\
\hline $\mathrm{Ya}$ & 3 & 7,5 & 0 & 0 & 3 & 7,5 & \multirow{2}{*}{0,01} & \multirow{2}{*}{0,92} \\
\hline Tidak & 17 & 42,5 & 20 & 50 & 37 & 92,5 & & \\
\hline \multicolumn{9}{|l|}{ Hari ke-2 } \\
\hline Ya & 0 & 0,0 & 1 & 2,5 & 1 & 2,5 & \multirow{2}{*}{1,14} & \multirow{2}{*}{0,29} \\
\hline Tidak & 20 & 50,0 & 19 & 47,5 & 39 & 97,5 & & \\
\hline \multicolumn{9}{|l|}{ Hari ke-3 } \\
\hline Ya & 2 & 5,0 & 1 & 2,5 & 3 & 7,5 & & \\
\hline Tidak & 18 & 45,0 & 19 & 47,5 & 37 & 92,5 & 0,31 & 0,58 \\
\hline
\end{tabular}

Tabel 6. Hubungan antara Kejadian Hipoglikemia dengan Rapid Acting Insulin Hari Pertama Saat Sarapan, Makan Siang, dan Makan Sore

\begin{tabular}{|c|c|c|c|c|c|c|}
\hline Kejadian Hipoglikemia Hari ke-1 & Rerata & SE & SD & \multicolumn{3}{|c|}{$\mathbf{p}$} \\
\hline \multicolumn{7}{|l|}{ Sarapan } \\
\hline Ada & 10,00 & 0,00 & 0,00 & 2,9732 & 0,0059 & *** \\
\hline Tidak Ada & 8,06 & 0,65 & 3,50 & & & \\
\hline \multicolumn{7}{|l|}{ Makan siang } \\
\hline Ada & 10,00 & 0,00 & 0,00 & 1,1090 & 0,2765 & \\
\hline Tidak Ada & 9,03 & 8,70 & 4,70 & & & \\
\hline \multicolumn{7}{|l|}{ Makan Sore } \\
\hline Ada & 10,00 & 0,00 & 0,00 & 3,0956 & 0,0043 & *** \\
\hline Tidak Ada & 8,23 & 0,57 & 3,10 & & & \\
\hline
\end{tabular}




\section{Pembahasan}

Diabetes Melitus tipe 2 yang merupakan penyakit progresif memiliki karakteristik penurunan fungsi beta pankreas yang saat ini meningkat angka kejadiannya terutama pada pasien yang berusia relatif muda. Oleh sebab itu, terapi insulin dibutuhkan dalam penatalaksanaannya karena memiliki keuntungan bahwa insulin terdapat di dalam tubuh secara alamiah. Selain itu, penatalaksanaan insulin dapat diberikan sesuai dengan pola sekresi insulin endogen (PERKENI, 2011 a).

Responden pada penelitian ini terbagi menjadi kelompok kontrol dan kelompok intervensi. Karakteristik responden baik pada kelompok kontrol dan kelompok intervensi meliputi jenis kelamin, pendidikan terakhir, status perkawinan, dan diagnosis medis. Pada hasil penelitian diperoleh jumlah responden wanita lebih banyak dibandingkan jumlah responden pria baik pada kelompok kontrol dan intervensi. Pendidikan terakhir terbanyak adalah tamat SLTA baik pada kelompok kontrol dan intervensi, dengan status perkawinan terbanyak adalah menikah dan terdiagnosis DM dengan penyakit penyerta. Sedangkan pada usia responden pada penelitian ini baik pada kelompok kontrol dan intervensi adalah di atas 50 tahun dengan lama menderita di atas 3 tahun dan lama dirawat di rumah sakit di atas empat (4) hari baik pada kelompok kontrol dan intervensi.

Selain memantau kadar glukosa darah dan jumlah insulin yang diterima, lembar pemantauan insulin terintegrasi memiliki kolom pemantauan kalori yang diterima pasien saat sarapan, makan siang, dan makan sore setiap harinya. Kebutuhan kalori pada responden pasien DM sebanyak 1700 kkal pada penelitian ini. Sedangkan asupan yang masuk ke dalam pasien rata-ratanya adalah $1500 \mathrm{kkal}$, sehingga dapat dilihat bahwa asupan pasien lebih sedikit dibandingkan dengan kebutuhan total kalori seharusnya. Asupan karbohidrat sangat diperhatikan pada pasien DM karena akan memengaruhi terapi insulin yang dibutuhkan, karena me- nurut perhitungan bahwa setiap 15 gram karbohidrat $=60 \mathrm{kal}=1$ unit insulin (PERKENI, 2011 b). Hal ini tampak pada sebaran insulin pada data hasil penelitian bahwa responden penelitian kelompok intervensi mendapatkan terapi insulin terbanyak jenis rapid dan long-acting insulin secara bersamaan yaitu sebanyak $27,5 \%$. Berbeda dengan kelompok kontrol yang memiliki terapi insulin jenis rapid-acting insulin saja atau diberikan long-acting insulin saja. Hal tersebut mempengaruhi kejadian hipoglikemia. Pada penelitian ini kejadian hipoglikemia terjadi lebih banyak pada kelompok kontrol yang lebih banyak mendapat terapi tunggal insulin baik rapid-acting insulin ataupun longacting insulin.

Variasi dosis insulin terdapat pada kelompok kontrol dan kelompok intervensi. Pada pemberian rapid-acting insulin, dosis insulin yang didapatkan oleh responden penelitian secara rerata adalah sebanyak 8 unit selama 3 hari pemantauan. Sedangkan rerata dosis insulin rapidacting pada pasien yang mendapatkan insulin rapid dan long acting sebanyak 9 unit selama tiga hari pemantauan. Perolehan dosis insulin yang didapat pada rapid-acting insulin sesuai dengan protokol PERKENI 2011 adalah 0,1 U/kg setiap makan porsi besar atau disesuaikan dengan jumlah karbohidrat yang dikonsumsi sesuai dengan perhitungan 15 gram karbohidrat $=60 \mathrm{kal}=1$ unit insulin .

Sedangkan pada responden yang mendapatkan long acting insulin saja mendapatkan rata-rata dosis insulin sebanyak 10 unit. Sehingga, pemberian terapi insulin jenis long-acting yang diberikan di RS Fatmawati sudah sesuai dengan protokol PERKENI tahun 2011. Pada protokol PERKENI 2011 menyampaikan bahwa terapi insulin sub-kutan jenis long-acting insulin perhitungan dosis insulin awal adalah 10 unit sebelum tidur, namun untuk keadaan yang dikhawatirkan terjadi hipoglikemia adalah sebanyak 5 unit (PERKENI, 2011).

Pada penelitian ini seluruh responden mendapatkan insulin sub-kutan. Insulin yang disun- 
tikkan dengan cara sub-kutan mencapai kadar insulin puncak yang membutuhkan waktu yang lebih lama. Hal tersebut dikaitkan dengan penurunan kadar glukosa darah awal yang lebih lambat serta timbulnya efek hipoglikemia lambat yang lebih sering dibandingkan dengan terapi insulin dengan cara sub-kutan.

Pada hasil penelitian berdasarkan analisis data kelompok intervensi, diperoleh hasil signifikan antara hubungan pemberian rapid-acting insulin saat makan sore di hari pertama pemantauan terhadap kejadian hipoglikemia. Hal ini diperoleh dari hasil analisis data dari uji t diperoleh nilai $\mathrm{t}=3,0956$ dengan nilai $\mathrm{p}=0,0043$ ( $\mathrm{p}<0,05)$. Penelitian yang dilakukan Braithwaite (2005) menunjukkan pada pasien yang mendapatkan dua kali premixed insulin atau basal insulin yang dikombinasikan dengan agen oral sebelum masuk rumah sakit akan diubah terapinya dengan basal prandial insulin dengan dosis koreksi selama penyembuhan pasien.

Penelitian ini memiliki keterbatasan seperti memerlukan jumlah sampel yang lebih banyak. Penelitian ini sudah sesuai dengan jumlah sampel yang dibutuhkan pada kelompok kontrol dan kelompok intervensi yaitu sebanyak 20 kelompok kontrol dan 20 kelompok intervensi. Peneliti mendapatkan jumlah sampel tersebut berdasarkan perhitungan dengan menggunakan proporsi yang digunakan oleh penelitian sebelumnya di luar Indonesia. Hal ini menjadi masukan untuk penelitian selanjutnya untuk mengetahui proporsi kejadian hipoglikemia terlebih dahulu di Indonesia untuk mengetahui jumlah sampel yang tepat dalam melihat keefektifan lembar pemantauan insulin terintegrasi.

Selain itu keterbatasan penelitian ini terdapat dalam proses pengambilan data dan analisis data. Peneliti merencanakan pemantauan menggunakan lembar pemantauan insulin terintegrasi selama tujuh hari. Selama proses pengambilan data responden pada kelompok kontrol dan intervensi dipantau selama tujuh hari. Namun, efektifitas pemantauan dilakukan selama tiga hari karena saat pengolahan data hari ke-4 sam- pai hari ke-7 data glukosa darah harian sudah tidak dilakukan lagi berdasarkan order dokter yang merawat karena kondisi pasien telah stabil.

Hal ini sesuai dengan etik penelitian, bahwa penelitian yang dilakukan tidak merugikan responden karena disesuaikan dengan keadaan pasien di rumah sakit. Sehingga, data yang diperoleh dan dapat diolah adalah data pemantauan selama tiga hari baik pada kelompok kontrol maupun kelompok intervensi.

\section{Kesimpulan}

Pada penelitian ini diperoleh hasil bahwa lembar pemantauan insulin terintegrasi tidak efektif untuk mengurangi kejadian hipoglikemia. Hasil penelitian menunjukkan bahwa terdapat hubungan signifikan antara pemberian rapidacting insulin saat makan sore dengan kejadian hipoglikemia melalui pemantauan lembar insulin terintegrasi.

Penelitian ini rekomendasikan pengembangan lembar pemantauan insulin terintegrasi dalam penelitian selanjutnya melalui berbagai tahapan aktivitas yang memungkinkan perawat untuk lebih memahami pengkajian hipoglikemia pada pasien diabetes melitus tipe 2 sehingga dapat meningkatkan keterampilan berpikir kritis dalam menginterpretasikan hasil temuan pengkajian pada lembar pemantauan insulin terintegrasi (MS, YU, INR).

\section{Referensi}

Achtmeyer, C.E., Payne, T.H., \& Anawalt, B.D. (2002). Computer order entry system decreased use of sliding scale insulin regimens. Methods of Information in Medicine. 41, 277-281.

American Diabetes Association. (2011). Clinical practice recommendations-executive summary: Standards of medical care in diabetes. Diabetes Care, 34 (Suppl. 1), S9-S10. 
Baldwin, D., Villanueva, G., McNutt, R., \& Bhatnagar, S. (2005). Eliminating inpatient sliding-scale insulin: A reeducation project with medical house staff. Diabetes Care. 28, 1008-1011.

Black, J.M., \& Hawks, J.H. (2009). Medical surgical nursing: Clinical management for positive outcome (8th Ed.). USA: Saunders Elsevier.

Braithwaite, S. 2006). The transition from insulin infusions to long-term diabetes therapy: The argument for insulin analogs. Seminars and Thoracic Cardiavascular Surgery, 18, 366-378. Elsevier Inc.

Center for Disease Control (2007). National diabetes fact sheet. Retrieved from: http://www.cdc.gov/diabetes/pubs/pdf/n dfs_2007.pdf.

Fischer, K., Lees, J., \& Newman, J. (1986). Hypoglycemia in hospitalized patients. The New England Journal of Medicine., 315 (20), 1245-1250.

Furnary, A.P., Wu, Y., \& Bookin, S.O. (2004). Effect of hyperglycemia and con- tinuous intravenous insulin infusions on outcomes of cardiac surgical procedures: The Portland Diabetic Project. Endocrine Practice, 10 (Suppl 2), 21-33.

Lien, L.F., Spratt, S.E., Woods, Z., Osborne. K.K., \& Feinglos, M.N. (2005). Optimizing hospital use of intravenous insulin therapy: Improved management of hyperglycemia and error reduction with a new nomogram. Endocrine Practice, 11, 240-253.

PERKENI. (2011a). Konsensus Pengelolaan Diabetes Mellitus di Indonesia. Jakarta: PB. PERKENI.

PERKENI. (2011b). Petunjuk praktis terapi insulin pada pasien diabetes mellitus. Jakarta: PB PERKENI.

Rymaszewski, H.L., \& Breakwell, S. (2013). A retrospective review of sliding scale vs. basal/bolus insulin protocols. The Journal for Nurse Practitioner, 9 (4), 214-218. https://doi.org/10.1016/j.nurpra.2013.03.00 1.

Sastroasmoro, S., \& Ismael, S. (2010)..Dasardasar metodologi penelitian klinis (Edisi ke-3). Jakarta : Sagung Seto.

Smith, W., Winterstein, A., Johns, T., Rosenberg, E., \& Sauer, B. (2005). Causes of hyperglycemia and hypoglycemia in adult inpatients. American Journal of Health System Pharmacy, 62 (7), 714-719.

Trence, D.L., Kelly, J.L., Hirsch, 1.B. (2003). The rationale and management of hyperglycemia for in-patients with cardiovascular disease: Time for change. The Journal of Clinical Endocrinology and Metabolism, 88, 2430-2437.

World Health Organization. (2008). Diabetes. Retrieved from http://www.who.int/media centre/factsheets/fs 312/en/index.html. 